\title{
Restructuring Financial Sector Supervision: Creating a Level Playing Field
}

\author{
Michel Flamée and Paul Windels \\ CBFA, Rue du congrès 12-14, Brussels 1000, Belgium. \\ E-mails: michel.flamee@cbfa.be, paul.windels@cbfa.be
}

During the past few years, the financial industry has been characterised by an ongoing cross-sector and cross-border consolidation of financial institutions spanning banking, securities, and insurance institutions and the blurring demarcation of their respective products and instruments. Against the backdrop of these changes, the creation of a level playing field for financial services has become a key challenge for policy makers, regulators, and market participants alike. At different national and international levels, regulators, and supervisors have been responding to this challenge with a plethora of measures. This paper presents a number of initiatives at different supervisory levels in view of recent financial sector developments and discusses how the challenge of a level playing field is being tackled.

The Geneva Papers (2009) 34, 9-23. doi:10.1057/gpp.2008.36

Keywords: level playing field; globalisation; supervisory challenges; integrated supervision; cooperation

\section{Financial sector supervision in an era of change}

The ongoing cross-sector and cross-border consolidation of financial institutions including new financial conglomerates has led to a blurring of distinctions between financial sectors and national financial markets. ${ }^{1}$ Against the backdrop of these changes, the creation of a level playing field for financial services has become a key challenge and a central point of attention for policy makers, regulators and market participants alike. A plethora of measures have been launched by many countries and organisations around the world in the desire to offer higher levels of competition, transparency, equal access and greater financial stability. The most notable example is the establishment of the European single market in financial services with the possibility to offer identical arrangements across the EU. To this end, the European Commission has launched a financial services policy, which clearly focuses on an integrated, open, inclusive and competitive financial market. ${ }^{2}$

At a national level, many countries have been considering the institutional structures of financial regulation in order to safeguard a level playing field between financial institutions. For many years, the architecture of financial supervision reflected a traditional approach, with separate agencies for banking, securities and

\footnotetext{
${ }^{1}$ Group of Ten (2001); Zalm (2005).

${ }^{2}$ European Commission (2005).
} 
insurance supervision. However, during the past few years there has been a substantial shift from the traditional sector-by-sector approach to supervision towards consolidation of supervisory powers leading to a prudential supervision of the main segments of the financial sector conducted by a unified agency. The rationalisation of the supervisory framework can be partly considered as a response to the rapidly changing institutional environment, which is characterised by an increasing integration of the banking, securities and insurance markets, as well as their respective products and instruments. ${ }^{3}$ Often substantial changes in the supervisory architecture have been made in the pursuit of efficiency, effectiveness and enhanced convergence of supervisory practices. ${ }^{4}$

However, the recent financial market turbulence has also shown the emergence of a number of supervisory challenges on a more global level. The need has arisen for supervisors in different jurisdictions and financial sectors to work more closely together to compare and align regulatory approaches for similar activities. In this regard, international standard-setters such as the International Association of Insurance Supervisors (IAIS) together with its sister regulatory organisations, the Basel Committee and International Organisation of Securities Commissions, have been supporting the creation of a level playing field so that similar risks are addressed by similar regulation and regulatory arbitrage is avoided. Through its various projects the IAIS has promoted international supervisory cooperation in order to improve the efficiency of insurance supervision and reach a higher level of economic efficiency. Confronted with these global challenges, the U.S. Treasury has released a Blueprint for Financial Regulatory Reform, which displays the canvas for a profoundly adapted financial regulatory system.

This paper presents a number of challenges at different supervisory levels in view of recent financial sector developments and discusses how some of these challenges are being tackled. First, a short review of supervisory challenges at the European level is presented. Then, the paper discusses the adoption of the integrated supervisory model at the national level including key arguments for and against this model. This is followed by some reflections on global supervisory challenges referring to the work of the IAIS and the U.S. Treasury's Blueprint for Financial Regulatory Reform. Then the paper concludes.

\section{Supervisory challenges at the European level}

The Financial Services Action Plan 1999-2005 5 laid the foundations for a strong financial market in the EU through the establishment of a largely harmonised set of financial regulations. In 2001, this was complemented with the Lamfalussy Framework to secure a more consistent and effective regulatory system across financial services (banking, insurance, and investment services). The institutional structure of the Lamfalussy Framework consists of four levels spanning from the development of

\footnotetext{
${ }^{3}$ Čihak and Podpiera (2006).

${ }^{4}$ Masciandaro and Quintyn (2008).

${ }^{5}$ European Commission (1999).
} 
general Framework Directive norms, technical implementation measures, guidelines, and best practices for the application of the legislation. Through the intervention of regulatory and supervisory committees in specific phases, a very different approach for the approval of European legislation has been introduced involving the European Commission in all levels, while reinforcing market consultation.

As outlined in the Report on Financial Supervision issued by the Financial Services Committee, ${ }^{6}$ current challenges to improve supervisory arrangements in the EU include (1) fostering supervisory cooperation and convergence, (2) enhancing the costefficiency of the EU system and (3) improving cross-border supervision. Particularly, the three committees composed of EU financial supervisors (known as the "Level 3 Committees") assume a key role in meeting these challenges. By drawing up guidelines for the administrative regulations to be adopted at the national level these committees foster a coherent transposition of first and second level legislation into national law. ${ }^{7}$ Although considerable progress has been made over the past few years in achieving a higher level of supervisory convergence, several concerns for the further development of the supervisory framework have arisen in relation to current market developments. ${ }^{8}$

As cross-border banking integration is gaining momentum in Europe the interdependence between different countries increases significantly. The potential of "spill-over effects" where a problem in the banking system of one country is likely to affect multiple participants in other countries or cause a system failure, forms a real threat. As a result, the monitoring of cross-border risk has become a critical issue while the practicalities of supervision and crisis management are greatly complicated. ${ }^{9}$ In contrast to these evolutions, financial stability arrangements in Europe have remained grounded at the national level. European financial supervisors are mostly concerned with the proper functioning of their national financial markets with the European dimension only being taken into account in the form of intensified cooperation. While this largely historically grown institutional set-up was acceptable in the past, it has now become ill-adapted to fully capture the potential risks of European cross-border financial integration. ${ }^{10}$

With the presence of multi-jurisdictional financial institutions, cross-border financial stability concerns have soared. Yet, current supervisory arrangements are based on networks of national supervisors and an entirely non-binding approach to cooperation (using Memoranda of Understanding). These may not be appropriate to respond to a major crisis caused by failure of markets or large cross-border institutions. Clearly, the recent crises in the financial markets have not only shown the emergence of new risks resulting from financial innovation and global integration, but also the inability of national structures to keep these at bay. ${ }^{11}$ Furthermore, despite the

\footnotetext{
${ }^{6}$ Financial Services Committee (2006).

${ }^{7}$ Gualandri and Grasso (2006).

${ }^{8}$ Trichet (2007).

${ }^{9}$ Ingves (2007).

${ }^{10}$ Speyer and Walter (2007).

11 Veron (2007).
} 
design and delivering of convergent prudential policies and practices, the existing prudential framework for financial supervision does not offer a level playing field for European financial institutions. ${ }^{12}$ In many countries, the adoption of prudential policies has been influenced by national interests resulting in a differing rather than a harmonised set of best prudential practices. To the detriment of multi-jurisdictional institutions, consolidated financial supervision has not become a streamlined, consistent and coherent process. ${ }^{13}$

A range of hypotheses has been put forward for the further improvement of the European supervisory structure. At one extreme lies the creation of a new European supervisory institution complementing the existing national supervisory structures while limiting the direct activities to multi-jurisdictional firms. ${ }^{14}$ The other extreme essentially envisages the improvement of the status quo by giving greater powers to the Level 3 Committees. ${ }^{15}$ Between these extremes, a number of alternatives are being discussed such as the establishment of a lead supervisor system ${ }^{16}$ or a separate mandatory regime for multi-jurisdictional institutions only. ${ }^{17}$ Given the legal and political prerequisites, the establishment of a fully fledged Pan-European supervisor is likely to be the most challenging alternative to realise.

It has been argued that a formal solution for the organisation of cross-border supervision should be best delivered on the basis of practical experience. ${ }^{18}$ Essentially this involves a step-by-step approach that builds upon the existing institutional arrangements for supervisory cooperation in place. With this perspective, a first step would be to more fully exploit the potential of the Lamfalussy process in the enhancement of a European supervisory culture and practice. ${ }^{19}$ This could be done by strengthening the role of the Level 3 Committees and gathering sufficient political and technical support for the supervisory convergence process. A next step would then involve the move towards a lead supervisor concept offering a single point of contact for the prudential supervision of multi-jurisdictional firms while operating with a college of supervisors. ${ }^{20}$ Eventually, the lead supervisor system could evolve into a Pan-European supervisory institution as another layer of supervision in addition to the national authorities, with a clear mandate vis-à-vis large cross-border institutions. ${ }^{21}$

\section{Supervisory challenges at the national level}

Around the world, governments have been reviewing the institutional structures of financial regulation or are considering substantial changes on the grounds that existing

\footnotetext{
12 Čihak and Decressin (2007).

${ }^{13}$ European Banking Federation (2007).

${ }^{14}$ Ingves (2007); Speyer and Walter (2007).

${ }^{15}$ Inter Institutional Monitoring Group (2007).

${ }^{16}$ European Financial Services Round Table (2007).

${ }^{17}$ Veron (2007).

${ }^{18}$ Ferran and Green (2007).

19 Inter Institutional Monitoring Group (2007).

${ }^{20}$ Wymeersch (2007).

${ }^{21}$ Ingves (2007).
} 
structures may have become inappropriate. A classic assumption is that to be effective, the structure of the regulatory system needs to reflect the structure of the markets that are regulated..$^{22}$ Largely in response to the integration in the markets, an increasing number of countries show a trend toward integration of supervisory powers and have established a single supervisory authority. Various alternative models of integrated financial supervision have been developed ${ }^{23}$ making the supervisory landscape less uniform than in the past.

In the case of fully integrated financial supervision, for instance, a single agency is responsible for prudential supervision of all firms and for conduct of business regulation and supervision. Fully integrated supervision has been established in the United Kingdom with the Financial Services Authority, in Belgium with the Banking, Finance and Insurance Commission (CBFA) and also recently in Switzerland with the Federal Financial Market Supervisory Authority. Generally, there is no strong argument for any particular supervisory structure; there are only advantages and disadvantages of different set-ups depending on the conditions in a given jurisdiction. ${ }^{24}$ In the following, some key arguments for and against the adoption of integrated financial supervision are reviewed. ${ }^{25}$

\section{Arguments in favour of integrated financial supervision}

The most important set of arguments are based on efficiency gains, in particular the economies of scale, which seemed to be offered by merging multiple supervisory agencies. $^{26}$ Integrated financial supervision should increase efficiency by eliminating duplicated support functions, enhance effectiveness and offer broader synergies in the light of the rise of financial conglomerates. At the same time, the blurring distinctions between the different classes of financial institutions have urged the need to revise supervisory coverage to avoid regulatory gaps, to ensure competitive neutrality and to improve accountability. The latter arguments have been advanced predominantly in the context of a number of industrial countries. ${ }^{27}$

\section{The rise of diversified financial conglomerates}

The rise of financial conglomerates has raised the issue of how to supervise them efficiently and effectively. As the financial conglomerates cover a range of financial services, supervision typically has been fragmented over different specialised regulators. This fragmented supervision has raised concerns on the ability of supervisors to take a consolidated view and assess the overall risk the conglomerate is taking. The existence of financial conglomerates has also increased the importance of having a regulatory

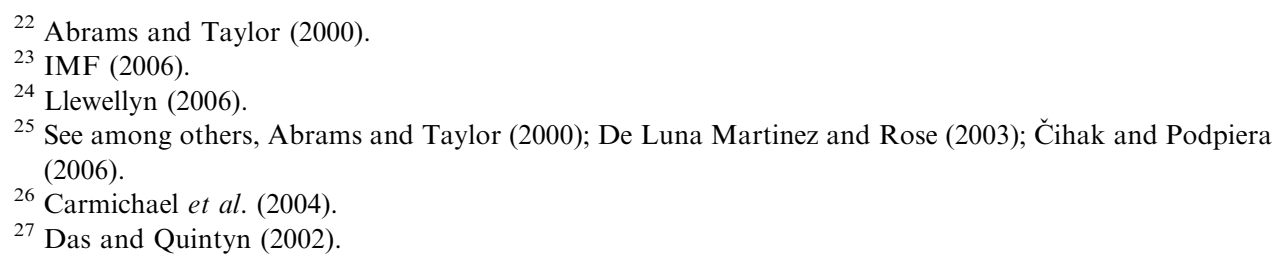


and supervisory framework that is consistent and free of gaps. In particular, supervisors must be able to respond on a conglomerate-wide basis should serious problems occur in any part of the conglomerate.

The recent developments place several requirements on the various financial supervisory bodies that are usually not well established. ${ }^{28}$ First, the supervisory bodies must have an effective system of information sharing with each other for each institution. Second, the supervisory bodies must develop a close working relationship and ensure that regulatory gaps are identified and closed. Third, for each institution a clear agreement should be made that one supervisor takes the lead both in forming an overall risk assessment and forming a regulatory response should problems arise.

Although the issues outlined above could be resolved by close cooperation of sectoral supervisors, an integrated supervisor is likely to be in a much better position to address them. The received information may be more smoothly exchanged in one institution and more quickly and effectively utilised. By becoming the only contact point for all regulatory and supervisory issues, the additional burden associated with fragmented supervision may be minimised for the conglomerates. This can be done by minimising overlap and duplication in reporting and oversight, and simplifying the process of decision-making.

\section{Competitive neutrality}

In terms of competitive neutrality, an integrated supervisor may be better able to ensure that similar financial products receive comparable regulatory treatment. As financial systems have evolved and matured, the differences between institutions and products have increasingly become blurred. Through the differences in regulation some financial service providers could obtain an unfair advantage while others would be tempted to engage in regulatory arbitrage. In the latter case, conglomerates would place particular products into the part of the conglomerate where the oversight or costs are the lowest. It may also lead firms to establish or redesign financial institutions to minimise supervisory oversight. If such attempts of regulatory arbitrage become widespread, this could lead to unhealthy forms of competition between sectoral supervisors in order to offer the most attractive supervisory regime. Clearly, these practices contrast with the current streams to harmonise supervision across sectors.

\section{Regulatory flexibility}

An integrated approach to supervision may allow for the development of regulatory arrangements that are more flexible than can be achieved with separate specialist agencies. A single agency can limit and control more effectively operational problems or doubts about the jurisdiction for dealing with a particular matter. An integrated supervisor may offer a better way to prepare and respond more effectively to the emergence of new products and services. This can be important for financial

\footnotetext{
${ }^{28}$ Abrams and Taylor (2000).
} 
innovation in industrialised countries, which is not covered by the existing legislation, as well as for ongoing structural changes of the financial systems in developing economies. In the context of rapid industry change, including the growth of non-bank financial intermediaries, a properly constituted integrated supervisor can profit from its scope and capacity to respond rapidly to changes by extending its regulatory jurisdiction.

\section{Economies of scale}

Economies of scale should lead to greater efficiency of operations of an integrated supervisor. Cost savings may be obtained on the basis of shared infrastructure, administration and support systems. Separate supervisory agencies have generally led to the duplication of support infrastructures such as data collection and personnel administration. Supervisory integration may lay the basis for a more efficient reporting system while using a more unified approach to data collection and avoiding unnecessary duplication of research. This could result in significant cost savings for the regulated enterprises, particularly financial conglomerates. Integration may also permit the acquisition of technologies, which become cost-effective only beyond a certain scale of operations and a greater specialisation of staff.

\section{Development of supervisory resources}

It is likely to be the case that an optimal staff deployment within an integrated agency would be easier to achieve than with a specialist and fragmented institutional structure. A large regulator should be able to attract, retain and develop a body of skilled professional staff. Moreover, it should be better placed to develop a consistent human resource policy, including a career planning strategy for its personnel. Integration also makes it easier for supervisors to share specialised knowledge across supervised sectors. First, it could foster the exchange of specialists between segments to support different supervisory functions. Second, efficiency gains may arise from the coordination of supervisory work on issues of mutual interest. Third, it may provide a solution for the shortage of supervisory resources, which seems to be a problem in a number of countries such as the Baltic States and Russia.

\section{Accountability of regulation}

A final argument for integrating supervision is that it may improve accountability. ${ }^{29}$ By creating a single regulatory agency, it becomes clear to the industry, the public and the other stakeholders who should be held accountable for regulatory actions and its performance, for the costs of regulation, for disciplinary policies and for regulatory failures. An integrated supervisor also becomes accountable for its statutory objectives eliminating the possibility of passing the blame to another supervisor if supervisory

\footnotetext{
${ }^{29}$ Masciandaro et al. (2008).
} 
failure occurs. However, the objectives of the integrated supervisor must be clearly specified in advance.

\section{Arguments against integrated financial supervision}

There are also a number of arguments against the integrated supervisory structure. First, the different supervisory functions may result in unclear or divergent objectives for the integrated regulatory agency. Second, economies of scope will prove hard to achieve as long as banking, insurance and securities remain subject to different regulations. Third, the integrated agency may also suffer from diseconomies of scale. Fourth, an integrated supervisor may extend moral hazard problems across the whole financial services sector. Lastly, the integration process itself may be poorly managed or become politicised.

\section{Unclear or divergent objectives}

As a result of the diversity of its objectives, ranging from guarding against systemic risk to protect consumers in particular sectors, a single regulator may not have a clear focus on the objectives and rationale for regulation. The statutory objectives may be ill-defined and not clearly communicated to all stakeholders resulting in a lower accountability of the supervisor. In some circumstances, a conflict could arise between the different objectives of a single regulator and inappropriate actions may be taken.

\section{Diseconomies of scale}

When the integrated agency becomes a very large organisation, it may become more bureaucratic and inflexible compared to smaller sectoral supervisors. In particular, this may be the case when the operations become so broad-based that the line managers are unable to understand the full range of operations of the organisation. A larger and more bureaucratic organisation may lead to diseconomies of scale. However, this issue is likely to be rather country-specific as an integrated supervisor of a small country may still be smaller than sectoral supervisors in large countries, which often seem to operate effectively.

\section{Limited synergies}

The synergies of supervisory integration are likely to be small when there are no substantial organisational and regulatory changes. It has been argued that the cultures, focus and skills of the various supervisors vary markedly. Often these latent differences of style and culture remain within the single organisation and form a big challenge for management in their attempt to create a single agency culture.

\section{Moral hazard}

The moral hazard argument is based on the premise that the public will tend to assume that all creditors of institutions under supervision of a given supervisor will receive equal 
protection. For instance, the creditors of other financial institutions may expect the same protection as the depositors in banks while this may not be appropriate. A clear communication strategy from the integrated supervisor would alleviate this problem partly. However, it seems necessary for the supervisor to reinforce its position by acting exactly in line with the pre-announced rules in specific cases of financial failures.

\section{Unpredictability of the integration process}

The unpredictability of the integration process itself may bring substantial risks. The first risk is that some powerful actors within the government will use the fact that the supervisory structure is open for discussion to push through the creation of a unified supervisor quickly. In this perspective, the proposal for integration will be seen as an opportunity to increase their influence within government by taking on important additional powers.

The second risk is that the creation of new legislation may open the possibility that the process will be captured by special interests in the financial sector to influence the process. Important issues that were settled may be reopened and eventually weaken the legislative outcome supporting the integrated supervisor. One way to minimise this potential problem is to establish a unified agency in a first stage with a transfer of powers from the existing regulatory bodies to it while leaving the sectoral legislation largely intact. The potential benefits of the harmonisation of legislation are then examined at a later stage.

The third risk is the possible reduction in regulatory capacity through the loss of key personnel. Many valuable members of the new organisation may view the integration as a time to test the job market or retire. This has been a serious problem in a number of countries as the staff with the highest potential is most likely to leave. This risk deserves particular attention if banking supervision is to be transferred from the central bank into a new agency.

The fourth risk relates to the difficulties of the change process itself. The management challenge of integrating different regulatory agencies should not be underestimated. A thorough change management plan needs to be developed at the outset of the change process. During the transition process itself, outside experts with the skills to bring about large-scale reorganisation may be engaged.

In short, the establishment of a single supervisory authority may offer substantial benefits to the organisation and execution of related supervisory work. The prudential supervision of financial conglomerates, for instance, could profit from the disposal of detailed information on the different activities and risks in the conglomerates as a whole. However, an integrated supervisory structure may also suffer some important disadvantages. For instance, in crisis situations, there could be tension between the increased transparency requirements arriving from financial market regulation and the impact of these measures from a prudential supervisory perspective, requiring appropriate arbitration. In such circumstances, the so-called Twin Peaks model of supervision, ${ }^{30}$ where prudential supervision is separated from conduct-of-business supervision, could be considered as more appropriate.

\footnotetext{
${ }^{30}$ Gorter and Moschsays (2008).
} 


\section{Global supervisory challenges}

During the past 18 months, systemic issues in the market place have shown that the financial system has become increasingly interlinked and vulnerable. A problem or weakness in one sector or country can easily spread to financial markets around the world increasingly requiring action to be taken at the global level. In this light, international supervisory organisations have been responding promptly with a number of actions. An important part of the global regulatory work has been taken up by the Financial Stability Forum (FSF) analysing the causes of the current crisis and making recommendations for action. ${ }^{31}$ Standard-setters and financial regulators have actively contributed to this work and to related cross-sectoral work conducted by the Joint Forum. As the international standard-setter for insurance supervision, the IAIS has delineated a number of activities as areas of high priority to enhance the supervision of international insurance companies ${ }^{32}$ and financial conglomerates.

\section{Cross-border and cross-sector cooperation}

The increasing integration of financial markets and the growing number of internationally active insurers and reinsurers has clearly made the need for mutual cooperation and information exchange more urgent. To this end, in 2007 the IAIS adopted a Multilateral Memorandum of Understanding for facilitating cross-border communication and the exchange of information between supervisors, where crossborder matters arise. While this has been an important step towards broadening contacts and trust among supervisors, more work is needed in the area of mutual recognition of supervisory systems. An effective system of mutual recognition would lead to greater reliance on home or host supervisors by each other, which would in turn reduce duplication of efforts. It is particularly in the reinsurance sector, due to its international nature, that progress will reap the greatest rewards.

The establishment of international colleges of supervisors for each of the largest global financial institutions should also lead to useful progress such as the development of best practice benchmarks. It should also quicken supervisory responsiveness in crisis situations. One could, however, question whether solely facilitating the exchange of information or cooperation among supervisors, and even agreements between authorities about burden-sharing in case something goes wrong, can suffice to cope with the consequences of a failure in a multinational environment where the free movement of services and of establishment is considered a strong promotion of economic development. While a burden-sharing mechanism may contribute to the optimal crisis resolution strategy, it could also increase the extent to which moral hazard is present in the system, which necessitates a clear discussion on the international level. In any case, close cooperation between regulators is essential to each supervisor and to the industry as a whole.

\footnotetext{
${ }^{31}$ Financial Stability Forum (2008).

${ }^{32}$ IAIS Annual Report 2007-08 (2008).
} 


\section{Inconsistencies between insurance and banking regulation}

The experience of the past few months has shown that an in-depth comparison of banking and insurance regulatory approaches would provide valuable regulatory insight. The IAIS is considering learning from potential deficiencies in the regulatory framework of the banking sector, including the need for cooperation between regulators and supervisors in times of crisis. Regulatory arbitrage between the banking and insurance sectors, for example, for structured credit products should be avoided. Bond insurers are currently subject to prudential requirements similar to those for other insurance entities, while their activities are economically much more comparable with banking activities than with insurance business. Further work on regulatory and supervisory requirements for credit insurance type products and others developments, such as the securitisation of insurance liabilities, will be considered in close cooperation with the banking regulators, so that similar risks are addressed by similar regulation and regulatory arbitrage is avoided.

\section{Principles-based supervision}

In order to cope with a globalising environment, the IAIS has assumed its responsibilities and has, as a global standard-setter, allowed for evolution from a traditional rules-based approach to supervision, often called the "box-ticking approach" to a principles-based approach. While some jurisdictions are particularly acquainted with a principles-based approach, for many others around the world it entails a new approach to supervision. Several efforts are being undertaken to educate and convince IAIS members of this new approach to supervisory action.

Principles-based regulation presents a number of challenges for both insurance companies and supervisors. For insurers, it implies a shift in focus, from managing a legally driven compliance process with detailed rules to managing the delivery of defined outcomes with fewer certainties about what processes need to be in place. As a result, greater responsibility is put on executive management, which needs to ensure that processes and controls are suitable for the business being undertaken and that the specified regulatory outcomes are met. In meeting these challenges, outcomes must be carefully monitored and processes increasingly require the exercise of professional judgment through transversal organisational functions such as risk management, internal audit, and compliance.

For supervisors, a principles-based approach involves a change in the extent and type of supervisory work undertaken. Instead of merely checking compliance with rules, supervisors need to exercise judgment in assessing organisational processes and controls in relation to the size and complexity of the business. Supervisory staff needs to understand complex issues and keep up to date with constantly changing markets and continuous innovation. In many instances, this requires an enlargement of the workforce and a further expansion of the knowledge, skills and capabilities in place.

\section{A common benchmark for solvency requirements}

Supervisory practices in the insurance industry are evolving towards new forms of risk-based solvency assessment and supervision. In particular, there is a shift towards 
the establishment of risk-based solvency assessment frameworks at a jurisdictional level. Currently, insurance supervisors in different regions and jurisdictions are at various stages of development in the establishment of risk-sensitive approaches to solvency assessment, such as on a regional level the EU work on Solvency II and the National Association of Insurance Commissioners Solvency Modernisation Initiative. On a national level revisions have been made to the capital framework in, for example, Australia, Bermuda, Canada, India, Korea, Singapore, Japan and Switzerland.

An important lesson of the recent financial crisis consists of the need for supervisors to evolve towards a globally accepted and applied set of solvency requirements. Essentially, this comes down to a streamlining of related supervisory work across borders and across sectors to allow for a smooth and fast supervisory action in crisis situations. In this regard, the IAIS is uniquely positioned to take advantage of the current jurisdictional initiatives, and to work with its membership to facilitate the development of a common global benchmark for risk-based solvency assessment. At present, the IAIS is completing the development of a cohesive set of standards on the solvency assessment of insurers on a solo basis. This will provide a strong foundation for the next stage of work on group-wide solvency assessment.

In addition to these key challenges, a number of actions are being envisaged in the short term in relation to the ongoing problems in the financial markets. In particular, ${ }^{33}$ a strengthening of the supervision of insurance companies, groups and their holding companies is considered with respect to credit risk, liquidity risk and the application of partial models for structured products. Furthermore, more time will be invested in the ongoing discussion on harmonised insurance guarantee schemes to foster market confidence.

\section{Supervisory challenges in the United States}

In the United States, the financial regulatory structure can be seen as a complex patchwork of federal and state level regulators, each established to have specialised functions in a particular segment of the financial markets. However, the sector rationale for regulation has lost its attraction against the backdrop of the financial market problems and the evolving international regulatory agenda. The financial regulatory authorities have been responsive to the recent problems with a number of different initiatives. Perhaps the most important was the release of the Treasury's Blueprint for Financial Regulatory Reform. The Blueprint can be considered a necessary step towards a more comprehensive and effective regulatory structure.

The Blueprint provides regulatory objectives with a link between the structure and the reasons of the regulation. The proposed model is developed around three regulators with a specific and complementary mission: a first regulator is concerned with market stability across the entire financial sector; a second regulator focuses on

\footnotetext{
${ }^{33}$ Steffen (2008).
} 
safety and soundness of those institutions supported by a federal guarantee; and a third regulator has the responsibility for protecting consumers and investors. The model allows easy adaptation and response to the changing demands of financial institutions, investors and markets because its structure is driven by regulatory objectives rather than by financial institution category. For instance, it allows the development of a federal policy on international matters, such as collateral requirements for internationally active (re-)insurance groups.

The Treasury views the presentation of a tangible model for an optimal structure as essential to its mission to promote economic growth and stability. In this respect, the proposed regulatory objectives aim to reinforce the direct relationship between strong consumer protection and market stability on the one hand and capital markets competitiveness on the other. Apart from a series of short-term and intermediate-term recommendations to improve the U.S. regulatory structure, the model is intended to begin a discussion about rethinking the current regulatory structure and its goals. In this respect, the proposed Blueprint can be seen as a first step on a long path to reforming financial services regulation in the United States.

\section{Conclusions}

In a perfect world, regulations should be equivalent across jurisdictions, consistent and comparable across sectors, applied in a uniform manner by different entities and enforced fairly and objectively. In reality, regulatory and supervisory arrangements differ considerably between jurisdictions and regions, which seriously complicate the management of cross-border financial institutions. It has been acknowledged that the lack of a level playing field between financial services generates much cost for firms, their users and regulators alike while it brings little benefit. In response to this important problem, a number of regulatory and supervisory initiatives have been taken up at different national and international levels.

At the European level, a framework for supervisory cooperation has been established, based on a common legislative process in the form of European Economic Community-directives and regulations to further build on. Although the Level 3 Committees have made real progress in achieving supervisory convergence, a further effort is needed to increase supervisory cooperation. This may imply a sound legal basis for the Level 3 Committees and an improved capacity for action. Important questions also arise on the degree of standardisation that is needed to create a level playing field for multi-jurisdictional institutions. In this light, a more profound examination of the main objectives and mandates for supervisors on a European level seems imperative.

Largely in response to the integration in the markets, several countries have adopted a unified supervisory structure as a new way to supervise their financial sectors. Individual country cases have suggested a number of advantages and disadvantages in relation to integrated supervision. Generally, the move towards integrated supervision seems to deliver promising results. Cross-country analysis has indicated that the benefits of integrated supervision may outweigh the costs for economies with a small or relatively geographically concentrated financial sector such as in the United 
Kingdom with London, Japan with Tokyo and Belgium with Brussels. ${ }^{34}$ A case can also be made for countries, which have significant domestic examples of financial conglomerates spanning banking, insurance and securities. ${ }^{35}$

The financial market turbulences have shown the emergence of a number of supervisory challenges at the global level. At present, supervisory arrangements are not designed to prevent or deal in an efficient and effective way with the cross-border externalities that financial crises may result in. The need has arisen in creating a broader structure of ongoing monitoring and mutual cooperation, to ensure that multi-jurisdictional firms with severe exposure are managed carefully. In this regard, the establishment of international colleges of supervisors is seen as an important initiative. A clear focus on the regulatory outcomes and required supervisory practices may lead to the further development of more convergent regulatory approach and a streamlined supervisory landscape. ${ }^{36}$

\section{Acknowledgements}

The views expressed in this paper are those of the authors and not necessarily those of the CBFA.

\section{References}

Abrams, R. and Taylor, M. (2000) Issues in the unification of financial sector supervision, IMF Working Paper 00/213, Washington, DC.

Carmichael, J., Fleming, A. and Llewellyn, D. (2004) Aligning Financial Supervisory Structures with Country Needs, Washington, DC: World Bank.

Čihak, M. and Decressin, J. (2007) The case for a European banking charter, IMF Working Paper 07/173, Washington, DC.

Čihak, M. and Podpiera, R. (2006) Is one watchdog better than three? International experience with integrated financial sector supervision, IMF Working Paper 06/57, Washington, DC.

Das, U. and Quintyn, M. (2002) Crisis prevention and crisis management: The role of regulatory governance, IMF Working Paper 02/163, Washington, DC.

Davies, H. and Green, D. (2008) Global Financial Regulation: The Essential Guide, Cambridge: Polity Press.

De Luna Martinez, J. and Rose, T. (2003) International survey of integrated financial sector supervision, World Bank Policy Research Working Paper 3096, Washington, DC.

European Banking Federation (EBF) (2007) Reflections on Level 3 of the Lamfalussy Process, Letter to the Inter Institutional Monitoring Group (EC) on their 2nd Interim Report, Brussels.

European Commission (1999) Financial Services: Implementing the Framework for Financial Markets: Action Plan, COM 232, Brussels: EC.

European Commission (2005) White Paper on Financial Services Policy 2005-2010, Brussels: EC.

European Financial Services Round Table (EFR) (2007) Monitoring Progress in EU Prudential Supervision, available at http://www.efr.be/pages/research.asp.

Ferran, E. and Green, D. (2007) Are the Lamfalussy Regulatory Networks Working Successfully? European Financial Forum, London: European Policy Forum Ltd.

Financial Services Committee (FSC) (2006) Report on Financial Supervision, Francq Report II, Brussels.

Financial Stability Forum (FSF) (2008) Report of the Financial Stability Forum on Enhancing Market and Institutional Resilience, available at http://www.fsforum.org.

\footnotetext{
${ }^{34}$ Čihak and Podpiera (2006).

${ }^{35}$ Foot (2006).

${ }^{36}$ Davies and Green (2008).
} 
Foot, M. (2006) 'Restructuring UK financial supervision: The UK experience', in N. Courtis and P. Nicholl (eds) Central Bank Modernization, London: Central Banking Publications Ltd.

Gorter, J. and Moschsays, R. (2008) 'The appeal of twin peaks', The Financial Regulator 13(1): 53-60.

Group of Ten (2001) Consolidation in the Financial Sector, Basel: Bank for International Settlements.

Gualandri, E. and Grasso, A. (2006) 'Towards a new approach to regulation and supervision in the EU: PostFSAP and Comitology', in Financieel Forum/Bank-en Financiewezen, Vol. 3, Brussels: Larcier.

IAIS (2008) Annual Report 2007-08, Basel, IAIS, October.

IMF (2006) Spain: Financial Sector Assessment Program - Technical Note - Supervision of Insurance: Alternative Models for an Independent Agency, Country report no. 06/217, Washington, DC.

Ingves, S. (2007) Regulatory Challenges of Cross-border Banking - Possible ways forward, Speech at the Reserve Bank of Australia, 23 July, Sydney: the Reserve Bank of Australia.

Inter Institutional Monitoring Group (IIMG) (2007) Second Interim Report Monitoring the Lamfalussy Process, European Commission, available at http://ec.europa.eu/internal_market/finances/committees/ index_en.htm.

Llewellyn, D. (2006) Institutional Structure of Financial Regulation and Supervision: The Basic Issues, paper presented at the World Bank Seminar: Aligning Supervisory Structures with Country Needs, 6-7 June, World Bank, Washington, DC.

Masciandaro, D. and Quintyn, M. (2008) Helping hand or grabbing hand? Supervisory architecture, financial structure and market view, IMF Working Paper 08/47, Washington, DC.

Masciandaro, D., Quintyn, M. and Taylor, M. (2008) Financial supervisory independence and accountability Exploring the determinants, IMF Working Paper 08/47, Washington, DC.

Speyer, B. and Walter, N. (2007) Towards a New Structure for EU Financial Supervision, Deutsche Bank Research EU Monitor, Vol. 48, Frankfurt am Main: DB Research.

Steffen, T. (2008) Recommendations for the ECOFIN Summit in Nice, 12-13 September, Nice.

Trichet, J.-C. (2007) Towards the Review of the Lamfalussy Approach: Market Developments, Supervisory Challenges and Institutional Arrangements, Speech at the First CEBS Conference, 9 May, London.

Veron, N. (2007) Is Europe Ready for a Major Banking Crisis? Bruegel Policy Brief, Vol. 3, Brussels: Bruegel Publications, available at http://www.bruegel.org/Public/Publication_detail.php?ID = 1169\&publication ID $=4530$.

Wymeersch, E. (2007) Speech at Belgisch Financieel Forum, 18 June, Brussels: Nationale Bank van België.

Zalm, G. (2005) Blurring of Distinctions: The Policy Response, Speech at the conference: Integrated Supervision of Financial Conglomerates: Challenges for the Future, May 12, Amsterdam: De Nederlandsche Bank.

\section{About the Authors}

Michel Flamée is the Vice-President of the Banking, Finance and Insurance Commission of Belgium, Chair of the Executive Committee of the International Association of Insurance Supervision, Member of the FSF G7 and Chair of the Convergence Committee of CEIOPS. He holds a Ph.D. degree in Law and is Professor in Economic and Financial Law at the Free University of Brussels (VUB).

Paul Windels is financial analyst and auditor at the Banking, Finance and Insurance Commission of Belgium. He holds a Ph.D. degree in Applied Economics and is Assistant Professor in Finance and Risk Management at the Hogeschool-Universiteit Brussel (HUB). 